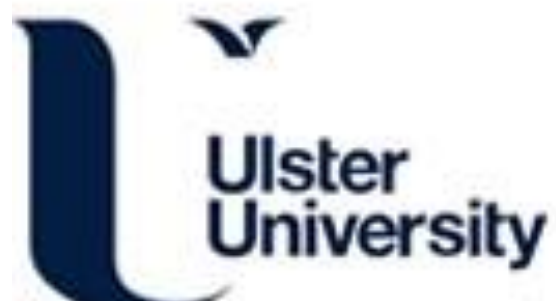

\section{Localized deposition of metallic molybdenum particles in ambient air using atmospheric-pressure microplasma}

Shimizu, Y., Koga, K., Sasaki, T., Mariotti, D., Terashima, K., \& Koshizaki, N. (2007). Localized deposition of metallic molybdenum particles in ambient air using atmospheric-pressure microplasma. In Unknown Host Publication (pp. 174-175)

Link to publication record in Ulster University Research Portal

Published in:

Unknown Host Publication

Publication Status:

Published (in print/issue): 08/11/2007

\section{Document Version}

Publisher's PDF, also known as Version of record

\section{General rights}

Copyright for the publications made accessible via Ulster University's Research Portal is retained by the author(s) and / or other copyright owners and it is a condition of accessing these publications that users recognise and abide by the legal requirements associated with these rights.

\section{Take down policy}

The Research Portal is Ulster University's institutional repository that provides access to Ulster's research outputs. Every effort has been made to ensure that content in the Research Portal does not infringe any person's rights, or applicable UK laws. If you discover content in the Research Portal that you believe breaches copyright or violates any law, please contact pure-support@ulster.ac.uk. 


\title{
Localized deposition of metallic molybdenum particles in ambient air using atmospheric-pressure microplasma
}

\author{
Yoshiki Shimizu $^{1}$, Kenji Koga ${ }^{2}$, Takeshi Sasaki ${ }^{1}$, Davide Mariotti ${ }^{1}$, Kazuo Terashima ${ }^{3}$, Naoto Koshizaki ${ }^{1}$ \\ 1: Nanoarchitectonics Research Center (NARC), National Institute of Advanced Industrial Science and \\ Technology (AIST), AIST Tsukuba Central 5, 1-1-1 Higashi, Tsukuba, Ibaraki 305-8565, Japan \\ 2: Nanotechnology Research Institute (NRI), National Institute of Advanced Industrial Science and \\ Technology (AIST), AIST Tsukuba Central 5, 1-1-1 Higashi, Tsukuba, Ibaraki 305-8565, Japan \\ 3: Department of Advanced Materials Science, Graduate School of Frontier Science, \\ The University of Tokyo, 5-1-5 Kashiwanoha, Kashiwa, Chiba 227-8562, Japan \\ Phone: +81-29-861-6333, FAX: +81-29-861-6355, E-mail: shimizu.yoshiki@aist.go.jp
}

\section{INTRODUCTION}

Our group is developing atmospheric microplasma deposition method using a metal wire as raw materials. In this method, a metal wire inserted in a microplasma generation nozzle is etched or evaporated by the generated microplasma, and the resultant active species are transported downstream and condensed on a localized area of the substrate [1-3]. However in this process, the resultant active species were inevitably oxidized by Oxygen trapped in ambient air. Accordingly this method was useful for preparation of metal oxide nanoparticles (tungsten oxide and molybdenum oxide) and their deposition on a localized specific area of micron size in diameter. However, we could not apply this method to the deposition of metal nanopartciles. Recently, we improved this method and found the feasibility of the deposition of metallic molybdenum (Mo) particles in ambient air. In this paper, we will report the details of the deposition process and the unique structure of metallic Mo particles obtained under specific conditions.

\section{EXPERIMENTS}

Figure 1 shows a schematic illustration of the apparatus. The aluminum tube (i.d. = submillimeter) was used as the nozzle for the microplasma generation. Mo wire (raw material) was inserted into the nozzle. Ar gas mixed with hydrogen was introduced into the nozzle, and ultra high frequency (UHF) at a few tens W was supplied to the coil through a matching circuit. The microplasma was stably generated and spouted out from the nozzle exit into ambient air. The substrate for deposition placed downstream was directly irradiated with the microplasma.

\section{RESULTS}

Figure 2 depicts a whole image of a typical deposit on a substrate, as observed with optical microscopy. The vaporized species from the Mo wire was condensed in about $1 \mathrm{~mm}$ diameter area. In case that the gas flow rate, UHF power and gap distance were under certain conditions, star-shaped particles, as in Figure 3, were densely formed on the deposited area. In EDS measurement, the Mo spectrum was mainly detected, but a slight peak of Oxygen also appeared. To identify the crystalline phase, star-shaped particles deposited on a single-crystalline $\mathrm{MgO}$ substrate was characterized using XRD. A typical pattern is shown in Figure 4. Peaks corresponding to molybdenum oxide phase did not appear, but one peak, almost corresponding to the (111) plane of fcc metallic molybdenum, did appear. More detailed characterization about the chemical composition was performed using XPS. The results indicated that the surface of the as-deposited particles was oxidized, but the inside of the deposit is mostly metallic Mo. The microstructure of the star-shaped Mo particles was characterized with TEM and TED. Figures 5 (a) and (b) present a top view of an individual star-shaped Mo by TEM (a) and the corresponding TED pattern (b). The analysis of the complicated TED pattern indicated that the star-shaped Mo particles are five-fold symmetrical multiply twinned particle.

\section{REFERENCES}

[1] Y. Shimizu, T. Sasaki, A. C. Bose, K. Terashima, and N. Koshizaki, Surface \& Coatings Technol 200, 4251-4256 (2006).

[2] Y. Shimizu, A. C. Bose, D. Mariotti, T. Sasaki, K. Kirihara, T. Suzuki, K. Terashima, and N. Koshizaki, Jpn. J. Appl. Phys. 45, 8228 (2006).

[3] A. C. Bose, Y. Shimizu, D. Mariotti, T. Sasaki, K. Terashima, and N. Koshizaki, Nanotechnology 17, 5976 (2006). 


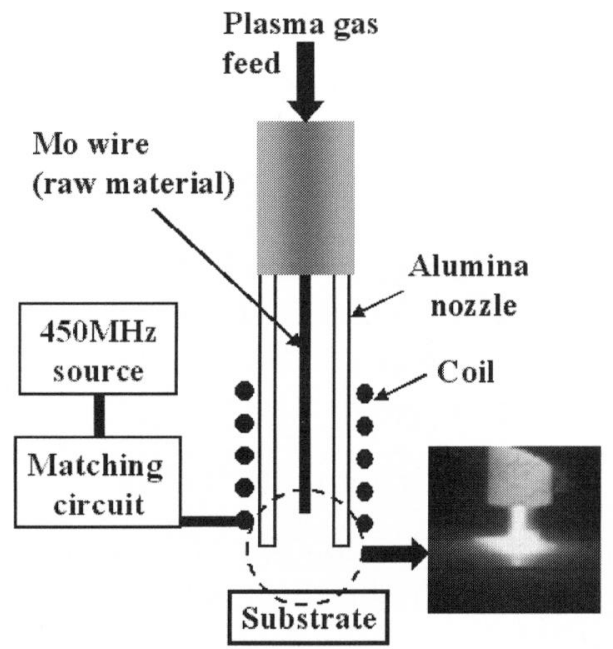

Fig.1 Schematic illustration of atmospheric pressure microplasma deposition system.

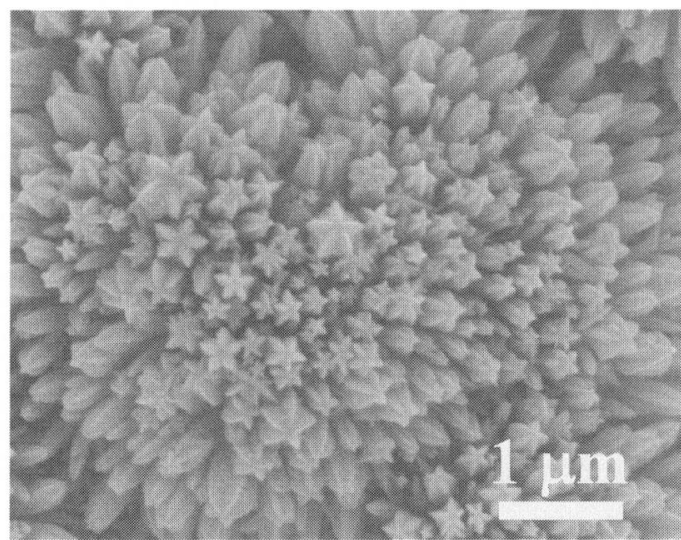

Fig.3 SEM image of the deposit. Star-shaped and pentagonal particles were densely formed on the area irradiated with atmospheric microplasma.
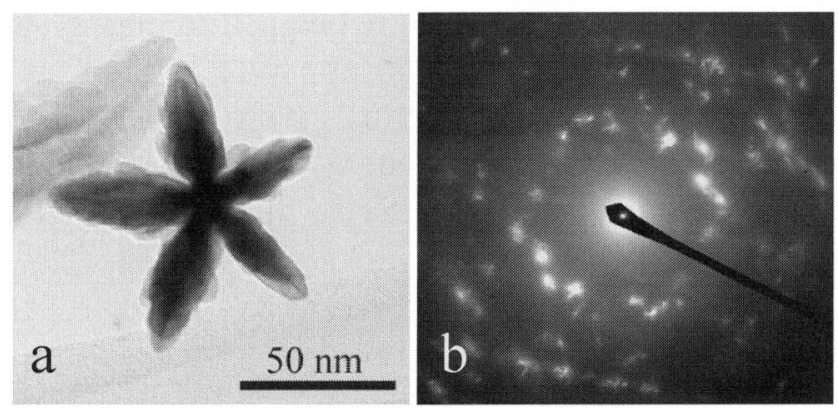

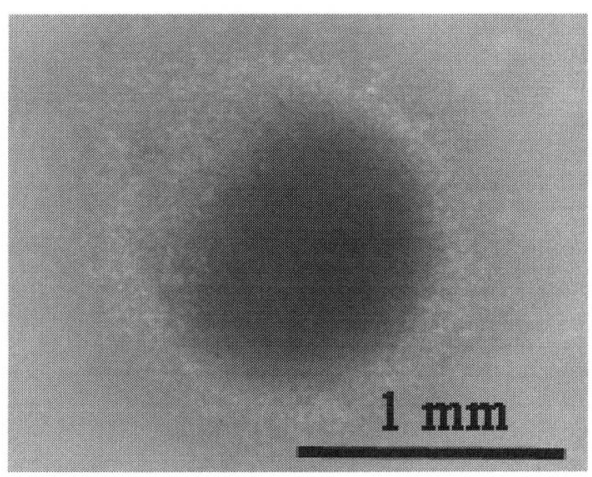

Fig.2 Optical microscope image of the deposit (top view).

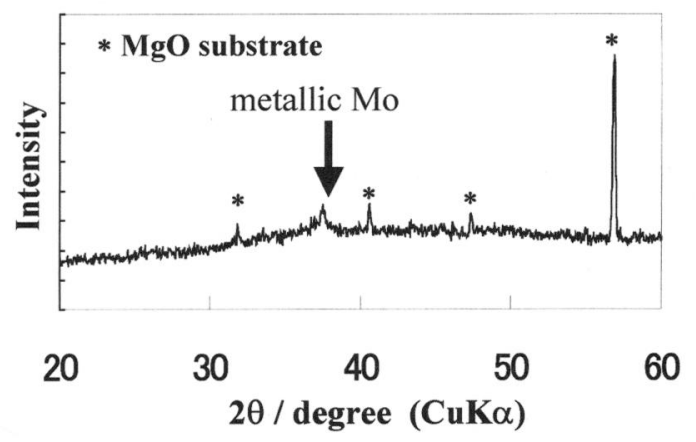

Fig.4 X-ray diffraction pattern of the star-shaped particles deposited on $\mathrm{MgO}$ substrate.

Fig.5 (a) Top view of an individual star-shaped Mo particle (by TEM) and (b) the corresponding TED pattern, indicating the star-shaped particle have 5-fold symmetrical multiply twinned structure.

\section{Acknowledgement}

This research was partially supported by a Grant-in-Aid for Scientific Research in Priority Areas: Generation of micro-scale reactive plasma and development of their new applications (microplasma), from the Ministry of Education, Culture, Sports, Science, and Technology, Japan. 